\title{
Spinal Cord Regeneration: New Experimental Approach
}

\author{
A. Hadi Khalili, MPhil, FACS, FRCS $($ Ed $),{ }^{1}$ M. Hayawi Hamash, MB, \\ CHB, PhD $^{2}$ \\ ${ }^{1}$ Assistant Professor, Department of Surgery (Neurosurgery), College of Medicine, \\ Baghdad University, Baghdad, Iraq. ${ }^{2}$ Assistant Professor, Department of \\ Anatomy, College of Medicine, Baghdad University, Baghdad, Iraq.
}

\begin{abstract}
Summary
An experimental study was conducted to enhance regeneration in the spinal cord. Twenty Swiss albino rats were used, of which 8 were controls, and hemicordotomy was performed at mid-thoracic level. In 12 rats a segment of peripheral nerve (sciatic) autograft was taken, minced and implanted in the hemicordotomy site.

All the rats were sacrificed at 4-12 weeks. Fixation was carried out by intracardiac perfusion of fixative. Light microscopy was used to study the hemicordotomy site. Two observations were made; first, regeneration of the cord was greatly enhanced, and second, the spinal cord caudal to the hemicordotomy did not disintegrate in the grafted cords.
\end{abstract}

Key words: Experimental spinal cord implants; Spinal cord injury.

Injury to the central nervous system which results in cell and tissue damage is always followed by a degree of degeneration. Regeneration in the central nervous system is known to be significantly limited (Windle, 1981). However researchers have studied the regeneration process in laboratory animals (Cajal, 1928; Collins 1983; Gerard and Kapponyi, 1926; Kao, 1970; Verra, 1981).

Gerard and Kapponyi in 1926 studied regeneration of spinal cord in rat fetuses. Subsequently, research to enhance regeneration has increased (French, 1962; Hughes, 1984; Meinecke, 1985; Wilson, 1984).

It was Cajal, in 1914 and in 1928, who first suggested that implantation of pieces of peripheral nerve into wounds in the central nervous system, might result in some regeneration activity. Sugar and Gerard in 1940 implanted pieces of peripheral nerves into wounds in the central nervous system of immature animals, and found a definite tendency to regeneration.

More recently this regeneration phenomenon has been further studied by many workers (Aihara, 1970; Kao, 1974; Kao et al., 1970, 1977a, 1977b). They grafted nervous tissues from the cerebellum, nodose ganglion and sciatic nerve into the transected spinal cord.

Their results indicated that grafted peripheral nerve tissue enhanced the regeneration ability in the spinal cord, more than other types of tissue. 
In this study, a sciatic nerve autograft was used in rats, but a different technique from Kao's was applied. In his work, Kao used the sciatic nerve segment (in experiments on dogs) with strict orientation of proximal/distal ends of the transplanted sciatic nerve segments (Kao, 1974).

The objective in this study was to disregard orientation of the grafted nerve segment, because graft orientation is technically difficult during surgery and to maintain after surgery in spite of the use of plasma gel. The method was to mince the nerve segment and to use the material as a graft. Hence the technique was more simple and reproducible. The results obtained were comparable to those obtained by Kao.

\section{Materials and methods}

Twenty adult Swiss albino rats were used in this study. The first group (controls) included 8 rats in which hemicordotomy was done without grafting. In the second group (12 rats), hemicordotomy was performed and sciatic nerve tissue was grafted into the wound.

Anaesthesia was induced by ether and maintained by intraperitoneal injection of Urethane. For the operation the animal was placed in the prone position, and a mid-thoracic skin incision was made. The paraspinal muscles were separated from the vertebrae. With the aid of operating microscope (Ziess OPMI 6), a hemilaminectomy was done on the right side, and the dura matter was exposed and opened. A through and through stab was made at the mid-thoracic level to sever the right half of the cord, using No. 11 surgical blade, and taking care not to extend the stab beyond the midline. Haemostasis was achieved by using gel foam, and diathermy. The mid thoracic level was selected as a high throracic cut caused immediate respiratory arrest and death in two of the rats. After completion of the experiment, the dura was left opened, covered only by a layer of gel foam and the incision was closed by water tight suturing of the muscles and of the skin using $4 / 0$ silk.

In the second group, the sciatic nerve was exposed ipsilaterally after a hemicordotomy was carried out. A segment of the tissue about $5 \mathrm{~mm}$ in length was cut and placed on a watch glass under the operating microscope, to be minced by sharp microscissors. The segment was cut in all direction until no real shape of the segment was left. The minced sciatic nerve tissue was grafted into the hemicordotomy wound. Any excess of grafted tissue which bulged above the surface of cord was wiped away with gel foam.

The animals were kept for 4-12 weeks after the operation and were then sacrificed after being anaesthetised with ether. The chest cavity was opened and the heart was exposed and perfused by $0.9 \%$ saline followed by $\frac{1}{4}$ strength of Karnovsky-gluteraldehydeparaformaldehyde fixative (Karnovsky, 1965). The spinal cord was then exposed and examined under the dissecting microscope. Segments from the cord at the site of the operation, and also proximal and distal to it were cut and refixed in a fixative containing: Saturated picric acid in $90 \%$ alcohol $70 \%$ in volume; $40 \%$ formaldehyde $25 \%$ in volume; and Trichloracetic acid $5 \%$ in volume.

The tissue was then dehydrated in absolute alcohol, embedded in paraffin 
and cut in 10 micron thick sections, which were then stained by a double impregnation silver technique (Fitzgerald, 1964).

\section{Results}

Gross findings: In the control group, the area of hemicordotomy, could be easily recognised by the presence of a trough-like depression and severe wasting of the caudal segment of the spinal cord. The spinal nerves and the spinal cord in this region were very friable and easily fragmented during the handling of the tissue for histological preparation.

In animals in which minced sciatic tissue was grafted into the wound, the healing of the spinal cord was very obvious and no, or minimal, wasting of the caudal segment was noticed. A lump of grafted tissue was seen on the surface in some cases.

Histological findings: In the control group, severe tissue necrosis and loss was seen at the region of cord section and distal to it (Fig. 1). A wide gap could be noticed with some invasion of connective tissue cells. Proximal to the site of transsection, there were signs of nerve degeneration for some distance, but some nerve sprouts could be noticed as fine fibres with terminal growing clubs. In general, the damage inflicted by hemicordotomy was much greater than expected, and there was no real healing, since the gap was very wide and the loss of tissue great.

In the grafted group the continuity of the proximal and distal segments of the

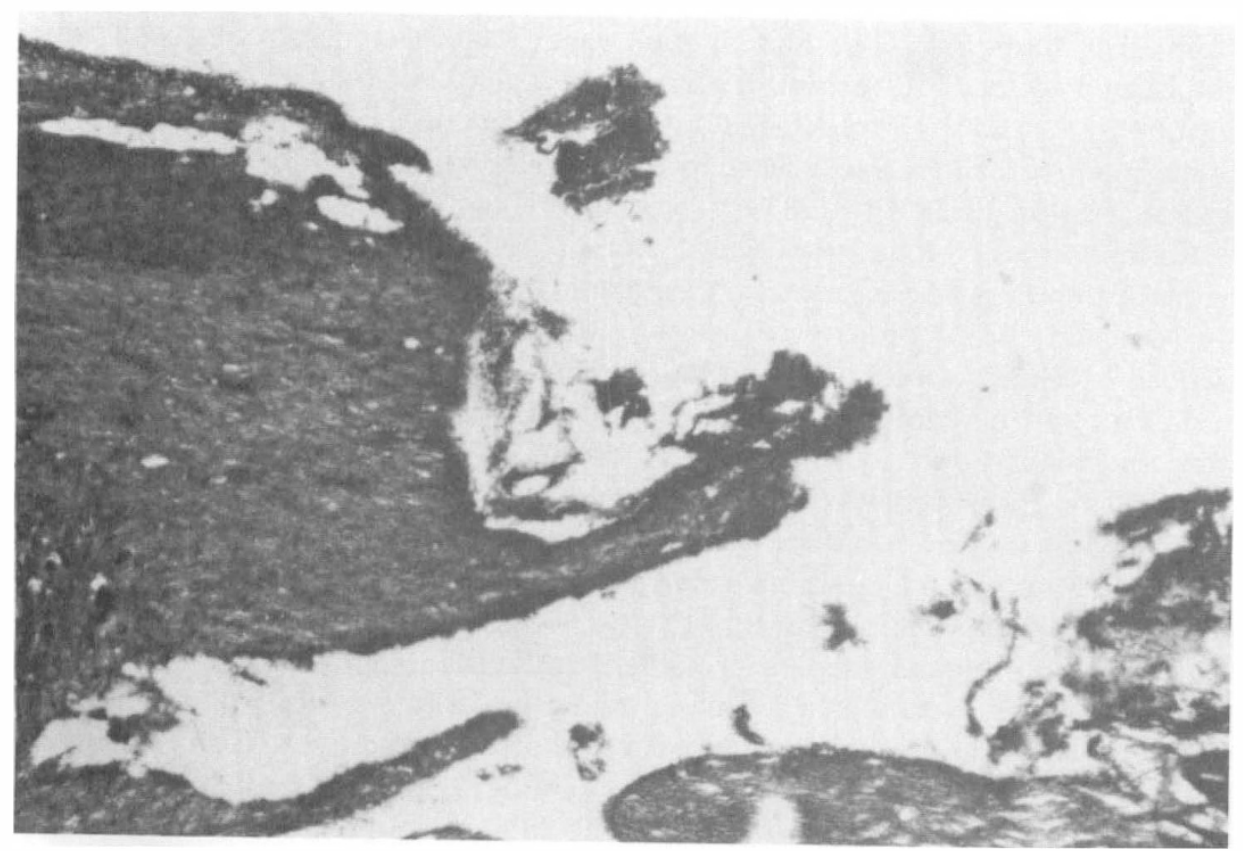

Figure 1 Photomicrograph of histological longitudinal section of control group showing gross necrosis in the distal segment. (X 100). 


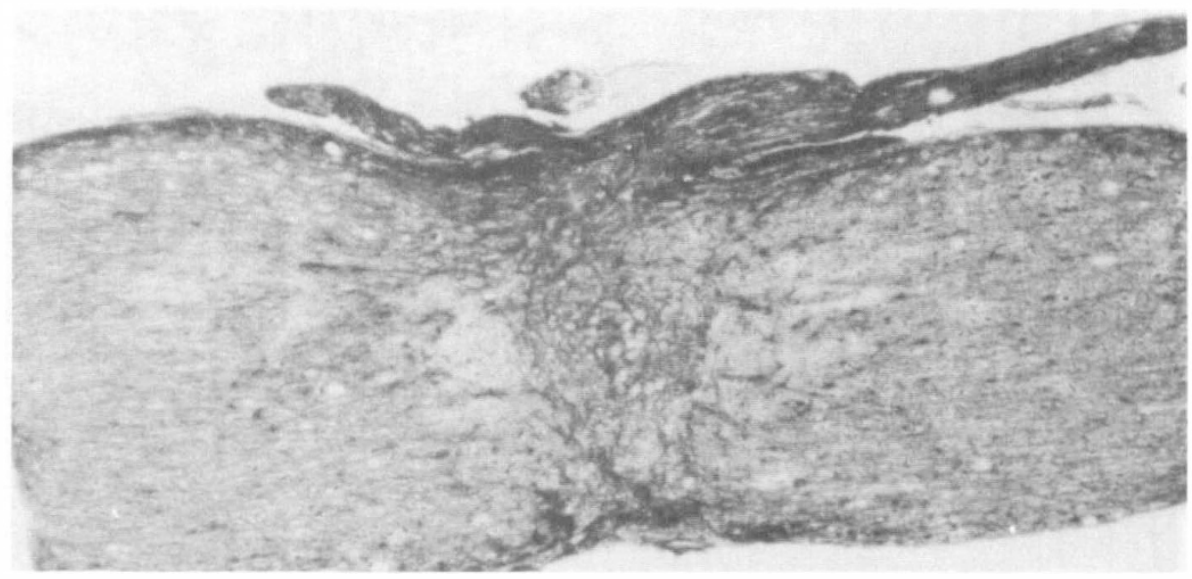

Figure 2 Photomicrograph of longitudinal section of spinal cord of grafted group showing the grafted tissue at the site of transection. Proper healing and preservation of integrity of distal segment is seen. (X 40).

severed spinal cord was restored with successful healing of the wound and minimal loss of tissue (Fig. 2). The distal segment appeared intact and was almost of normal diameter. The nerve fibres in this segment showed signs of degeneration and loss. Similar changes were also seen in the proximal segment for a short distance.

The grafted sciatic tissue was recognised easily by its stronger metachromatic property, but its bounderies were not easily definable. Cells and fibres were extending to (or from) the grafted tissue, from the spinal cord tissue (Fig. 3).

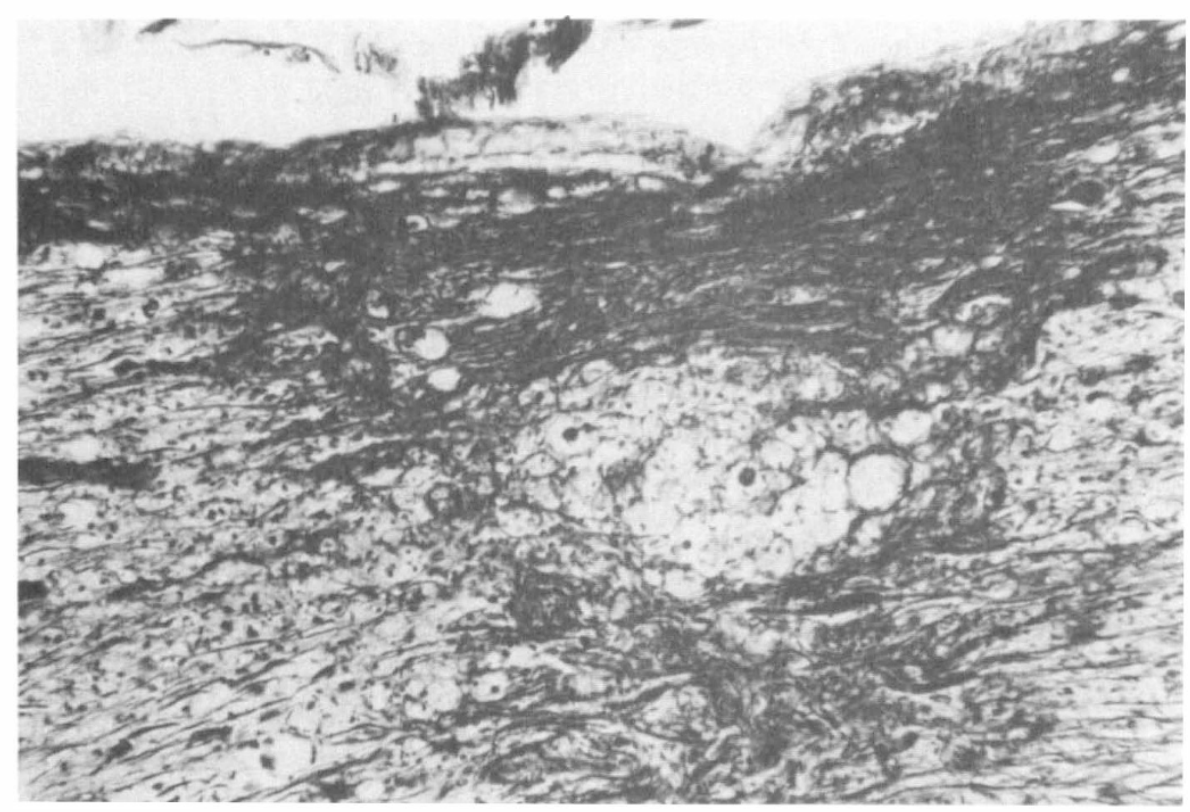

Figure 3 A section in the spinal cord of grafted group in which sciatic tissue graft is intermingling with the host tissue. (X 200). 


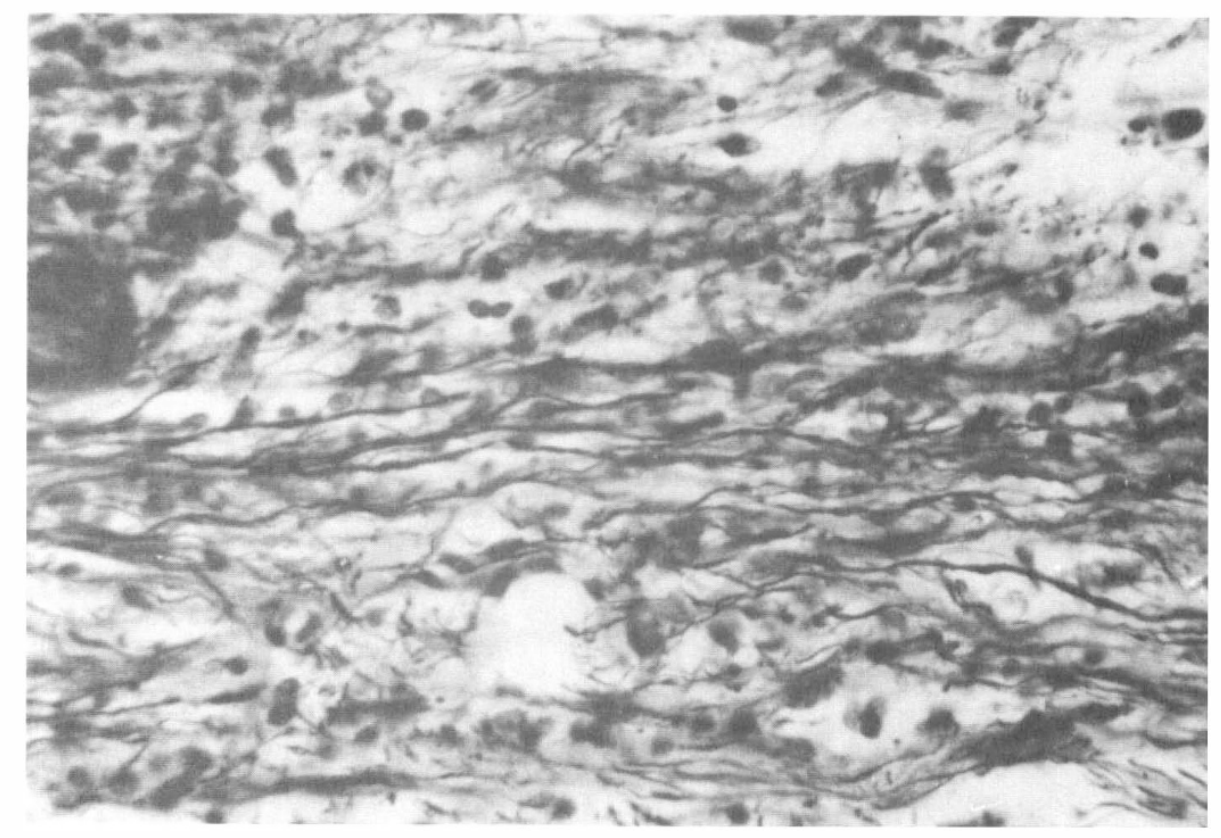

Figure $4 \mathrm{~A}$ photomicrograph of a section at the site of tissue graft in the spinal cord. Nerve fibre can be seen traversing the graft from proximal to distal segments. Areas of degenerating fibres can be seen in the adjcent areas. (X 320).

Regenerating nerve fibres could be recognised in this group as scattered fibres traversing the graft from the proximal segment toward the distal segment (Fig. 4). These growing fibres were usually of fine calibre with terminal clubbing and were closely associated with supporting neuroglial cells, characterised by stronger staining ability and probably from grafted tissue.

\section{Discussion}

A spinal cord wound produced by transection does not regenerate (Kao, 1974). This statement is known to be true in human beings sustaining a spinal cord injury, and also in laboratory animals. Studies of the regeneration process in human casualties would be impossible. The exact knowledge whether these were definite cuts, or were from other forms of tissue damage in the cord and its extent would be impossible to appreciate, even at the time of the surgical exposure. We can only study the process in experimental animals. Windle in 1981 , stated that answers to paraplegic research would not be found in hospital wards, but in the laboratories of the basic sciences.

In this study the results of spinal cord transection, in the control group showed that the continuity of the spinal cord was lost and no actual healing has occurred. These are in agreement with the studies of other workers (Guth and Windle 1970). The tissue damage at the site of transection was greater than what had been expected. This resulted from cystic formation and collection of fluid and leaking organalles from the damaged axon due to continuous axoplasmic flow. This flow continues for some time and, in later stages, terminal clubs were 
formed at the cut ends of these axons, resulting in the formation of micro cysts, which in turn rupture releasing organeles into the extracellular space, and autolysis of the spinal tissue took place because of the release of lyosomal enzymes. (Kao et al., 1977b; Martinez and Friede, 1970). The gap created will jeopardise any attempt of nerve regeneration from proximal to distal segments.

Comparing these degenerative changes with the results obtained from experiments in which minced sciatic tissues were grafted into the wound showed the marked advantages of the latter procedure: the healing process in the spinal cord was complete, as structural continuity was restored and the distal segment was morphologically preserved. The grafted tissue, survived and seemed to be interacting with the surrounding cord tissue, halting the degenerative changes which might lead to cyst gap formation. Restoration of structural continuity made the growth of regenerating nerve fibres in the spinal cord possible. This growth seemed to be enhanced by neurilemmal cells from the grafted tissue (Schwann cells). These cells appeared in sections closely associated with the regenerating fibres, and escorting these fibres through the empty spaces or through the graft tissue. Cells of the graft tissue may have another favourable function, by clearing the debries from tissue damage in the spinal cord transection (Richardson et al., 1980). Another important, possible role for the Schwann cells, is that they act as a trophic agent for the growing cones of the nerves. This was suggested by other workers (Liu, 1973). The possibility of the presence of some other unknown neurotropic factor in peripheral nerve tissues that may attract central nervous system neurites cannot be ruled out.

All these functions of the Schwann cells from the peripheral nerve graft seem to facilitate axonal growth and enhance regeneration (Liu, 1973).

The use of minced graft tissue in these experiments indicates that the orientation of sciatic nerve segment during grafting procedure (Kao, 1974) is not necessary, and probably that minced tissue is more beneficial because of the easy expansion of graft tissue to fill the space and of less likelihood of graft piece dislodgement.

In conclusion, two major advantages were achieved: first was halting of the degenerative process of the distal segment, and second the initiation of the regeneration of fibres across the transected segment of the spinal cord.

\section{Acknowledgement}

The authors wish to thank Mrs Maysoon Khourshed, Chief Technician, Department of Anatomy.

Thanks also extended to The Scientific Documentation Centre, Scientific Research Council.

\section{References}

AIHARA H 1970 Autotransplantation of the of the cultured cerebellar cortex for spinal cord reconstruction. Brain Nerve 22:769-784.

CAJAL RY 1928 Degeneration and regeneration of the nervous system. R.M. Amy [Trans.] London Oxford Press.

CAJAL RY 1914 Degeneration and regeneration del sistema nervioso, Madrid, Nicolas Moya, pp. 530-557.

Collins WF 1983 A review and update of experiment and clinical studies of Spinal cord injuries. Paraplegia 21:204-219. 
FITZGERALD MJT 1964 The double-impregnation silver technique for nerve fibres in paraffin sections. Quarterly fournal of Microbiological Science. 105:254-361.

FRENCH JD, PORTER RW 1962 Basic research in paraplegia. University of California Press, Los Angeles, USA.

Hughes JT 1984 Regeneration in the human spinal cord: A review of the response to injury of the various constituents of the human spinal cord. Paraplegia 22:131-137.

Gerard RW, Koppanyi T 1926 Studies on spinal cord regeneration in the rat. American fournal of Physiology 76:211-212.

GUTH L, WINDLE WF 1970 The enigma of central nervous regeneration. Experimental Neurology 28: supp. 5:1-43.

KAO CC 1974 Comparison of healing process in transected spinal cords grafted with autogenous brain tissue, sciatic nerve, and nodose ganglion. Experimental Neurology 44:424-439.

Kao CC, Chang LW, Bloodworth Jr TMB 1977 Axonal regeneration across transected mammalina spinal cord. An EM study of delayed microsurgical nerve grafting. Experimental Neurology 54:591-615.

Kao CC, Chang LW, Bloodworth Jr JMB 1977 Electron-Microscopic observations of the mechanisms of terminal club formation in transected spinal cord axons. Fournal of Neuropathological and Experimental Neurology 36:140-156.

Kao CC, Shimizu Y, Perkins LC, Freeman LW 1970 Experimental use of cultured cerebellar cortical tissue to inhibit the collagenous scar following spinal cord transection. Fournal of Neurosurgery 33:127-139.

KARNOVSKY MJ 1965 Formaldehyde-gluteraldehyde fixative of high osmolarity for use in electron microscopy. Fournal of Cell Biology 27:137.

LUI HM 1973 1. The origin in schwann cell during peripheral nerve regeneration. Fournal of Neuropathological and Experimental Neurology 32:456-473.

MARTINEZ AJ, FRIED RL 1970 Accumulation of axoplasmic organelles in swollen nerve fibres. Brain Research 19:183-198.

MEINECKE FW 1985 Some thoughts about neurological recovery in spinal cord injuries: A philosophical review. Paraplegia 23:78-81.

Richardson PM, MCGuinNes UM, Aguayo AJ 1980 Axons from CNS neurones regenerate into peripheral nerve grafts. Nature 284:264-265.

SUGAR O, GERARD RW 1940 Spinal cord regeneration in the rat. Fournal of Neurophysiology 3:1-19.

VERRA RP, GRAFSTEIN B 1981 Cellular mechanism for recovering from nervous system injury. A conference report. Experimental Neurology 71:6-75.

WILSON DH 1985 Peripheral nerve implants in the spinal cord in experimental animals. Paraplegia 22:230-237.

WINDLE WF 1981 Recollection of research in spinal cord regeneration. Experimental Neurology 71:1-5. 